\section{Fracture Strength of Weakened Anterior Teeth Associated to Different Reconstructive Techniques}

\author{
Mariana Carolina de Lara Ferro', Vivian Colucci', Artur Gaiotto Marques', \\ Ricardo Faria Ribeiro², Yara T. C. Silva-Sousa1, Erica Alves Gomes ${ }^{1}$
}

'School of Dentistry, UNAERP - University of Ribeirão Preto, Ribeirão Preto, SP, Brazil ${ }^{2}$ Department of Dental Materials and Prosthodontics, University of São Paulo, Ribeirão Preto School of Dentistry, Ribeirão Preto, SP, Brazil

Correspondence: Dra. Érica Alves Gomes, Av. Costábile Romano, 2.201, 14096-900 Ribeirão Preto, SP, Brasil. Tel.: +55-16-3603-7000. e-mail: ericaagomes@yahoo.com.br

\begin{abstract}
This study evaluated the fracture strength of endodontically treated teeth submitted to reconstructive techniques through dynamic and static tests. Forty human anterior teeth were divided into 4 groups $(n=10)$ : GNW (non-weakened) - root restored with glass fiber post (GFP), GW - weakened root restored with GFP, GDA - weakened root restored with direct anatomic GFP, and GIA - weakened root restored with indirect anatomic GFP. The teeth were endodontically treated considering that experimental groups (GW, GDA and GIA) simulated weakened roots for restoration with GFP using different techniques. The GFP was luted with resin cement and the coronal portion was restored with composite resin and metallic crowns. All samples were submitted to chewing simulation at 60 cycles/ min in a total of 300,000 cycles. The survival samples were further exposed to compressive loading at a crosshead speed of $1.0 \mathrm{~mm} / \mathrm{min}$ in a universal testing machine. The load was applied at $135^{\circ}$ to the long axis of the tooth until failure. Data were analyzed by ANOVA $(\alpha=0.05)$. After chewing simulation were observed: GNW: $100 \%$ of survival roots; GW: $70 \%$ of survival roots, and GDA and GIA: $80 \%$ of survival roots. The mean fracture strength values (N) were 280.6 (GNW), 239.0 (GW), 221.3 (GDA), and 234.1 (GIA) without significant difference among the groups ( $p=0.7476)$. The results suggested similar fracture strength in both weakened and non-weakened teeth regardless the reconstructive technique of root internal wall. Higher incidence of catastrophic fracture was observed in weakened teeth without restoration of the root internal wall.
\end{abstract}

Key Words: compressive strength, fatigue, post and core technique, tooth root.

\section{Introduction}

Endodontically treated teeth present high risk to biomechanical failures due to significant loss of tooth structure (1), as a result of extensive carious and noncarious lesions, previous restorations, trauma, fractures, iatrogenies, pulp pathologies and endodontic access (2). Depending on the severity of coronal structure destruction, if more than $50 \%$ is lost, the use of intraradicular retainers, such as metal core build-ups and prefabricated posts, should be required to provide retention of the restoration (3).

Glass fiber posts are less rigid and present mechanical properties similar to dentin, creating a homogeneous assembly within the root (4) with better stress distribution than metallic posts (5). In addition, the contact of metallic posts with interstitial fluids results in electrochemical reactions (1) as well as posts more rigid than dentin increase the risk of stress concentration in the apical region of the tooth, which cause a high incidence of irreparable fractures in restored teeth (5). Cast-metal cores fit well to the remaining root structure. But, they can produce a wedging action under masticatory forces, resulting in catastrophic root fractures (5).

The restoration of weakened roots with standard glass fiber posts (GFP) may failure as a consequence of misfit since the geometry of the weakened root results in a very wide, tapered, and un-retentive post (6). A thick cement layer can generate bubbles in the cement-post-dentin interface that lead to failure in bonding and cementation (8). In this sense, techniques using anatomic posts (8-16) have been suggested to achieve better fit between the post and root internal wall with less chance of debonding. Despite of the advances in adhesive restorative materials and prefabricated post systems, the restoration of severely weakened teeth remains controversial.

Many conclusions about the biomechanical performance of teeth restored with posts were based on static tests $(17,18)$. Although those findings are relevant, further studies are required to simulate the clinical scenario of dynamic loading (19). In this sense, in vitro fatigue simulation is an important tool for evaluation of restorative materials and techniques. Thus, the aim of this in vitro study was to evaluate the fracture strength after chewing simulation and static test as well as the failure mode of weakened endodontically treated teeth submitted to different reconstructive techniques of root internal wall. The null hypothesis assumed that: 1 - there is no significant difference between the non-weakened and weakened 
groups, and 2- there is no significant difference among the different reconstructive techniques of the weakened endodontically treated teeth.

\section{Material and Methods}

This study was approved by the Research Ethics Committee (C.A.A.E. 20878713.1.0000.5498). Human maxillary canines stored in $0.1 \%$ thymol solution at $4^{\circ} \mathrm{C}$, were cleaned and analyzed at a magnification of $10 \times$ with a stereomicroscope (Carl Mahr GmbH, Esslinger, Germany) to discard those with possible failures (fractures, fissures or cracks). Next, the teeth were radiographed and those without calcifications and resorptions were selected. The mesiodistal dimensions on cervical region of the roots were measured with a digital caliper (Carl Mahr) and 40 standardized teeth were selected.

After specimen selection $(n=40)$, the coronal portions of each tooth were removed to standardize the length of the specimens at $15 \mathrm{~mm}$ with a diamond disk (15HC, Buehler, Germany) using a sectioning machine (Isomet 1000; Buehler, Lake Bluff, IL, USA).

The root canal was explored to its full extension using a \#10 K-file (Dentsply-Maillefer, Ballaigues, Switzerland) until the tip coincided with the apical foramen, reducing $1 \mathrm{~mm}$ from the obtained measurement to determine a 14 $\mathrm{mm}$ real working length. The root canals were subjected to biomechanical preparation with ProTaper System (DentsplyMaillefer) using SX, S1, S2, F1, F2, F3, F4 e F5 at $250 \mathrm{rpm}$ (SA Anthogyr, Sallanches, France).

The preparation of root canal was performed using the rotatory tool (ProTaper; Dentsply-Maillefer) up to \#50/.02. The canal was irrigated with $2 \mathrm{~mL}$ of $1 \% \mathrm{NaOCl}$ after each change of instrument and final rinse with $5 \mathrm{~mL}$ of 17\% EDTA (DATERRA - Farmácia de Manipulação, Ribeirão Preto, SP, Brazil) for $5 \mathrm{~min}$, to remove smear layer. The canals were dried with absorbent paper points (Dentsply-Maillefer), sealed with gutta percha points (Dentsply-Maillefer) associated with an epoxy resin-based sealer (AH Plus Dentsply DeTrey, Konstanz, Germany).

After seven day storage at $100 \%$ humidity at $37{ }^{\circ} \mathrm{C}$, the root canal sealing material was partially removed with \#1 to \#3 Largo drills (Dentsply-Maillefer), removing $10 \mathrm{~mm}$ of the canal material and preserving $4 \mathrm{~mm}$ of the guttapercha at the apical region.

The roots were randomly assigned to four groups $(n=10)$ : Group GNW (control) - non-weakened root restored with GFP; Group GW - weakened root restored with GFP without reconstruction of the internal wall; Group GDA: weakened root restored with direct anatomic GFP; and Group GIA: weakened root restored with indirect anatomic GFP (Fig. 1).

Weakened root was simulated in the groups GW, GDA and GIA. The intracanal dentin was reduced using a diamond spherical drill \# 1016 (KG Sorensen, Barueri, SP, Brazil) (1.8 $\mathrm{mm}$ in diameter) up to $10 \mathrm{~mm}$ in deep and \#3017 HL (KG Sorensen) (2.5 $\mathrm{mm}$ in diameter) up to the medium third at $5 \mathrm{~mm}$ in deep (15). The remaining dentin thickness was standardized at $1 \mathrm{~mm}$ to simulate the hostile scenario of endodontically treated teeth and to create a circumferential space of $1 \mathrm{~mm}$ between the GFP $(1.5 \mathrm{~mm}$ in diameter, no 3) (Reforpost Fiber Glass; Angelus, Londrina, PR, Brazil) and the dentin wall at the medium and cervical thirds.

For simulation of the periodontal ligament, all roots were covered with a $0.5 \mathrm{~mm}$ uniform layer of polyether (Impregum Soft; 3M/ESPE) $2 \mathrm{~mm}$ below the cervical

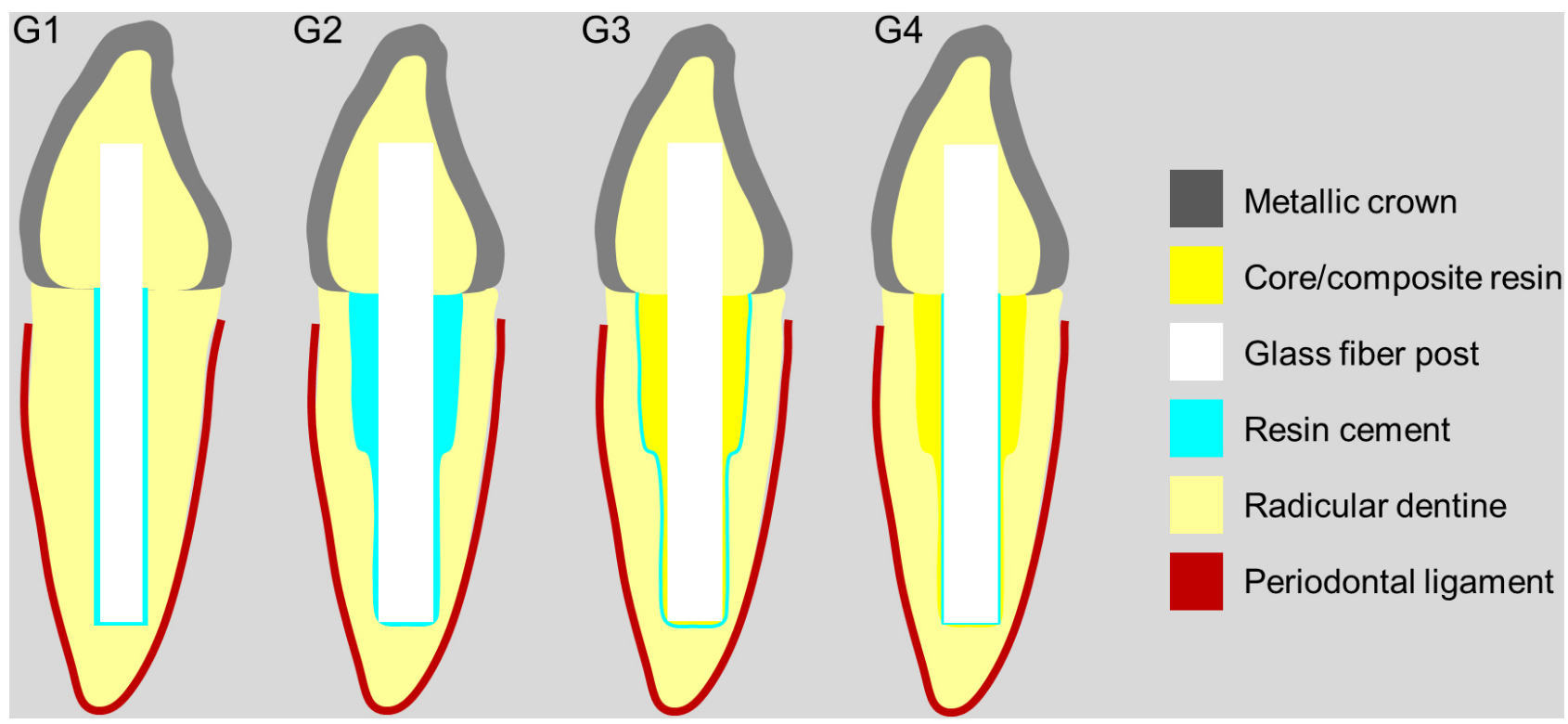

Figure 1. Different groups showing different reconstructive techniques with intracanal posts.. 
margin. A modified paralelometer (Bio Art Equipamentos Odontológicos Ltda, São Carlos, SP, Brazil) was used for positioning of the roots in the long axis into PVC tubes with $25 \mathrm{~mm}$ in diameter and $20 \mathrm{~mm}$ in height. The roots were embedded with a polyurethane-based material (Polyurethane for embedment F16; Axson, Cergy, France) $2 \mathrm{~mm}$ away from the cement-enamel junction to simulate the bone level.

The treatment of root dentin and GFP was standardized in all groups. Dentin was conditioned with $37 \%$ phosphoric acid (Condac, FGM, Joinville, SC, Brazil) for $15 \mathrm{~s}$, washed at the same time and dried with absorbent paper points. The adhesive system (Adper Single Bond 2; 3M/ESPE, St Paul, $M N$, USA) was applied into the canal with a microbrush (KG Sorensen), the excess was removed with paper cones and light cured for $10 \mathrm{~s}$ with a quartz-tungsten unit (650 $\mathrm{mW} / \mathrm{cm}^{2}$ power density) (Radii Plus SDI (North America) Inc., IL, USA). The GFPs were cleaned with alcohol and silane coupled (Ceramic Primer-Silano RelyX; 3M/ESPE) and then allowed to dry for $1 \mathrm{~min}$. Conventional dual resin cement (Rely X ARC; 3M/ESPE) was manipulated according the recommendations of the manufacturer and inserted into the root canal. The cement was also applied on the GFP that was inserted toward the tooth long axis in perpendicular direction using $250 \mathrm{~g}$ axial load during $30 \mathrm{~s}$ in a static device to simulate and standardize finger pressure.

In groups GNW and GW, the roots were restored as previously described. However in GW, the GFP presented diameter smaller than the root canal, resulting in thicker cement layer. In GDA (direct anatomic technique), a hydrosoluble gel (K-Y Gel; Johnson \& Johnson, São Paulo, $S P, B r a z i l)$ was applied into the root canal and, the fiber post was covered with composite resin (Z250; 3M/ESPE) and the set (composite resin and GFP) were inserted simultaneously into the canal. This set was replaced and removed twice, and the excess was removed. After light curing for $20 \mathrm{~s}$ with the GFP inside the root canal, the set was removed and the composite resin was additionally light-cured for $20 \mathrm{~s}$ on each surface. Then, the treatment of root dentin and GFP was accomplished as previously described.

In GIA (indirect anatomic technique), the root internal wall was previously reconstructed with composite resin so the GFP was cemented into the restored canal. In this technique, the canal was treated with the adhesive system and composite resin (Z250; 3M/ESPE) was inserted in layers with $2 \mathrm{~mm}$ in thickness. A light-transferring post (White Post; FGM Produtos Odontológicos, Joinville, SC, Brazil) with diameter similar to the canal was used as a reference to determine the space for the GFP after insertion and light curing of the composite resin layers.

The core was built up with a composite resin (Z250; $3 \mathrm{M} / \mathrm{ESPE}$ ) through incremental filling. Each increment of 2 $\mathrm{mm}$ was light cured for $20 \mathrm{~s}$. Then, the composite core was prepared using diamond drills (KG Sorensen), and finished and polished with Soft-Lex aluminum oxide discs (3M/ESPE). A matrix of condensation silicone (Zetaplus; Zhermack $\mathrm{SpA}$, Badia Polesine, RO, Italy) was used to standardize the fabrication of the resin composite core (Z250; 3M) ESPE) in all groups.

Forty metallic crowns in nickel-chromium alloy ( $\mathrm{Ni}-$ $\mathrm{Cr}$ ) (Verabond II; Aalba Dent. Inc., USA) were fabricated to simulate a maxillary canine. Each crown was waxed (Kota Indústria e Comércio, São Paulo, SP, Brazil) using a matrix of condensation silicone (Zetaplus; Zhermack) to standardize the fabrication of the metal crowns in all groups. Casting was accomplished using the lost-was technique. Then, the metallic crowns were sandblasted and finished with specific tools and paste for metal polishing. The crown adaptations were examined and cemented with zinc phosphate cement (S.S. White Artigos Dentários Ltda., Rio de Janeiro, RJ, Brazil). An axial load of $250 \mathrm{~g}$ was applied on the crown during $10 \mathrm{~min}$ in a static device to simulate and standardize finger pressure.

\section{Dynamic Fatigue Test - Chewing Simulation}

The samples were submitted to the fatigue test in a mechanical loading device developed in Department of Dental Materials and Prosthodontics of the School of Dentistry of Ribeirão Preto, Universidade de São Paulo. Five cylindrical structures in stainless steel with polished surface worked as antagonist surface. During the test, the chewing cycle accomplished three movements: 1 : downward vertical movement simulating incisal clenching, 2: lateral movement of $6 \mathrm{~mm}$ simulating laterality, and 3: upward vertical movement simulating opening. The replicas remained immersed in deionized water during the test conducted at $1 \mathrm{~Hz}$ with loading of $50 \mathrm{~N}$, totalizing 300,000 cycles; which represents one year of masticatory function (20).

At the end of the fatigue test, all samples were submitted to clinical, radiographic and were evaluated by using a stereomicroscope (Mitutoyo, Tokyo, Japan) at $40 \times$ magnification to check any crack or fracture. The number of survival samples after the fatigue test was recorded as a percentage (\%) of survival. Furthermore, the failure mode of the specimens was evaluated through qualitative analysis.

\section{Static Test of Fracture Strength}

The survival samples after chewing simulation were submitted to the static test of fracture strength in a universal testing machine (EMIC, DL 2000, Equipamentos e Sistemas de Ensaios Ltda, São José dos Pinhais, PR, Brazil) at a crosshead speed of $1 \mathrm{~mm} / \mathrm{min}$. The load was applied at $135^{\circ}$ degrees to the long axis of the tooth on the palatal 
surface of the tooth $2 \mathrm{~mm}$ away from the incisal edge until fracture. The load to failure was recorded in Newtons (N).

The failure mode of the samples was evaluated by qualitative analysis using clinical, radiographic exams, and a stereomicroscope (Mitutoyo, Tokyo, Japan) at $40 \times$ magnification and classified into: 1: repairable, including adhesive failure of core or root fracture above the bone level or at the cervical third; or 2: irreparable, including

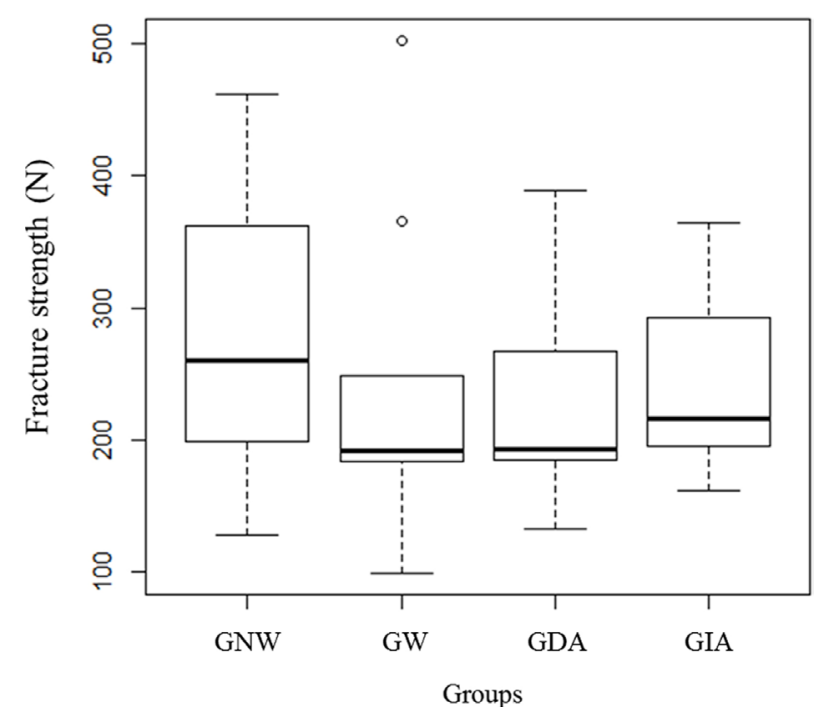

Figure 2. Boxplot of fracture strength of each group.

Table 1. Qualitative evaluation of failure mode distribution after dynamic fatigue test and static fracture strength test

\begin{tabular}{lccccc}
\hline & \multirow{2}{*}{$\begin{array}{c}\text { Failure } \\
\text { mode }\end{array}$} & \multicolumn{5}{c}{ Groups } \\
\cline { 3 - 6 } & GNW & GW & GDA & GIA \\
\hline $\begin{array}{l}\text { Dynamic } \\
\text { fatigue } \\
\text { test }\end{array}$ & Repairable & 0 & 0 & 2 & 2 \\
& Irreparable & 0 & 3 & 0 & 0 \\
$\begin{array}{l}\text { Static } \\
\text { fracture } \\
\text { strength }\end{array}$ & Retal & 0 & 3 & 2 & 2 \\
test & Irreparable & 0 & 1 & 2 & 2 \\
\hline
\end{tabular}

Table 2. Means and standard deviation (SD) of fracture strength (N) for each experimental group

\begin{tabular}{lcc}
\hline Group & N & Mean and SD \\
\hline GNW & 10 & $280.6(114.3)$ \\
GW & 7 & $262.6(132.6)$ \\
GDA & 8 & $230.5(79.5)$ \\
GIA & 8 & $243.8(69.7)$ \\
\hline
\end{tabular}

fracture at medium and apical third of the root.

\section{Statistical Analysis}

The fracture strength values were described as measures of central position and dispersion. The analysis of variance ANOVA was used for comparison among the groups. This model is applied for normal distribution of the residue with mean zero and constant variance. A $5 \%$ level of significance was used. The analyses were performed with the software SAS version 9.2.

\section{Results}

Dynamic Fatigue Test: Descriptive Analysis and Survival Results

Among all samples, seven specimens fractured during the dynamic fatigue test: three irreparable failures occurred in the GW groups, two repairable failures in the GDA group, and two repairable failure in the GIA group. The survival percentage of the samples after fatigue test for each groups was $100 \%$ of roots for GNW, $70 \%$ of roots for GW, $80 \%$ of roots for GDA and $80 \%$ of roots for GIA (Table 1).

\section{Static Test of Fracture Strength}

Sensitivity analysis was conducted considering the mean, standard deviation, and confidence interval (Table 2). There was no statistically significant difference among the groups ( $p=0.7476$ ) (Fig. 2). The qualitative evaluation of failure mode of each group is shown in table 1 .

\section{Failure Mode}

In the negative control group (GW), 40\% incidence of irreparable fractures were observed. In GDA and GIA groups, $80 \%$ of repairable fractures and only $20 \%$ of irreparable fractures were found. In the positive control group (GNW) $100 \%$ of repairable fractures was observed.

\section{Discussion}

Endodontic treated teeth, presenting extensive tissue loss, require the use of an intraradicular post to improve the retention of coronal restoration (3) and to promote a more homogeneous distribution of the occlusal load along remaining tooth structure (11). Depending on the degree of destruction of intraradicular dentin, several restoring techniques have been proposed, aiming to reduce the resin cement thickness and, consequently, the polymerization stress at the cement/dentin and cement/post interfaces (21).

The null hypothesis of the current study was accepted, since no differences were found among all restoring techniques tested. Similar fracture strength was noted both in weakened as nonweakened roots, regardless restoring protocol employed. Within the clinical conditions simulated in this study, it is believed that the similarity among elastic 
modulus of materials employed (fiber posts (30-40 GPa), resin cement (18.2 GPa) (22) and composite resin (20 $\mathrm{GPa}$ ) with dentin structure (15-25 GPa) assisted in shock absorption, accompanying flexural movements of the tooth (17), creating a monoblock able to homogeneously distribute the tensions, which increases tooth strength (9).

This result is in agreement with the studies of Silva et al. (10), Wandscher et al. (23) and partly according to the findings of Gomes et al. (12). Instead, the results contrast with those found by Zogheib et al. (8) and Barcellos et al (11).

Certain factors have to be considered and these studies should be compared with caution. Sometimes, studies used different types of teeth for analysis, which possess distinct root morphology. Some studies employing bovine teeth $(10,23)$ while others using human teeth $(8,11,12)$. Furthermore, studies employing teeth of similar species use either anterior teeth $(8,11)$ or posterior teeth $(12)$, which can lead to different results.

During clinical function, repetitive ordinary chewing forces affect dental elements over time, which makes the mechanical cycling indispensable to simulate the clinical conditions to which post-retained restorations are exposed (12). However, another aspect that needs to be addressed is that very few studies use standardized mechanical cycling, which may interfere in the results. Furthermore, restorative materials employed in different studies may differ in their chemical and mechanical properties, which complicates the comparison among the results obtained (13).

Although the methodology employed by Barcellos et al. (11) is the nearest one used in this study, with similarity in the kind of teeth used, in mechanical cycling and in the type of glass fiber post and materials employed, the disagreement between the results may be attributed to the size of the post. In that study (11), a 1.1-mm cervical diameter glass fiber post was employed. Instead, in the current study a $1.5-\mathrm{mm}$ cervical diameter post was used, which is in accordance with manufacturer's instruction, when human maxillary canines are restored. The fracture resistance values increase as the diameter of the fiber post increases (24).

The closer contact between resin cement and the dentin wall, promoted by better adaptation of the post, improve the contact area, which, consequently, increase the frictional retention (25). Additionally, the pressure during cementation increase with post-to-root canal adaptation (11), reducing porosity in the cement layer. This may help explain similar values obtained among positive and negative control groups in the current study.

The fracture mode is a highly important parameter to compare restoring techniques (11). Consistent with earlier findings $(10,12,16)$, the most of the fracture patterns observed in this study were repairable, in a general analysis.
The similar elastic modulus of the materials employed and dentin, besides the flexibility of the glass fiber posts prevents the propagation of microcracks and favors the distribution of the load along the root and periodontal support (14).

The fracture analysis suggests that the fracture resistance test used in this study was not sensitive enough to rank the different techniques. In the negative control group (GW), in which the roots were weakened and the glass fiber posts were cemented without rebuilding the walls with composite resin, the highest incidence of irreparable fractures (40\%) were observed. When resin cement layer is too thick, the polymerization stress at the cement/ dentin and cement/post interfaces may promote stress concentration zones induced by structural discontinuities (12), which may induce fracture lines reducing the tooth strength.

In the GDA and GIA groups, which had their roots weakened and rebuilt by direct and indirect anatomical technique respectively, it was observed the occurrence of $80 \%$ of reparable fractures and only $20 \%$ of irreparable fractures. Composite resin reduces stress concentrations at the interfaces, distributing forces in a more uniform manner, minimizing irreparable fractures (17), which improve the prognosis of post-retained restorations (19).

In the positive control group (GNW), in which the roots were not weakened, it was observed the occurrence of repairable fractures in 100\% of cases, suggesting that the preservation of healthy tooth structure is important in the restoration of endodontically treated teeth (11).

Although no statistically significant difference in static fracture strength was found, it was clearly shown higher incidence of catastrophic failure in GW during chewing simulation; which suggests that the resistance to fracture of endodontically treated teeth depends on the amount of remaining dentin (8). In this sense, it is important to preserve the root dentin of endodontically treated teeth restored with glass fiber post since a non-weakened root allows repair instead of tooth extraction. In addition, tooth structure must be preserved during intracanal preparation since the restorative materials are prone to failure and thicker layers may influence the long-term success (1).

According to the results and within the limitations of this in vitro study, it can be concluded that similar fracture strength was observed in both weakened and nonweakened teeth regardless the reconstructive technique of root internal wall. Additionally, weakened teeth without restoration of the root internal wall presented higher incidence of catastrophic fracture.

\section{Acknowledgements}

The authors wish to thank the Laboratory of Biomechanical Studies in 
Prosthodontics and Implants at the Department of Dental Materials and Prosthodontics of FORP-USP for technical support.

\section{Resumo}

Este estudo avaliou a resistência à fratura de dentes tratados endodonticamente submetidos a diferentes técnicas de reconstrução por meio de testes dinâmico e estático. Quarenta dentes humanos anteriores foram divididos em 4 grupos $(n=10)$ : GNW (não fragilizado): raiz restaurada com pino de fibra de vidro (PFV), GW: raiz fragilizada restaurada com PFV, GDA: raiz fragilizada restaurada com PFV anatômico direto, e GIA: raiz fragilizada restaurada com PFV anatômico indireto. Os dentes foram tratados endodonticamente considerando que nos grupos experimentais (GW, GDA e GIA) simulou-se fragilização radicular das raizes para restauração com PFV utilizando diferentes técnicas. Os PFV foi cimentados com cimento resinoso e a porção coronária foi restaurada com resina composta e coroa metálica. Todas as amostras foram submetidas a simulação de mastigação em 60 ciclos/min totalizando 300,000 ciclos. As amostras sobreviventes foram submetidas a teste de compressão com velocidade de $1,0 \mathrm{~mm} / \mathrm{min}$ em máquina universal de ensaio. A carga foi aplicada a $135^{\circ} \mathrm{em}$ relação ao longo eixo do dente até a falha do dente. Os dados foram analisados por ANOVA $(\alpha=0,05)$. Após a simulação da mastigação foi observado: GNW: $100 \%$ de sobrevivência das raizes; GW: 70\% de sobrevivência das raizes, e GDA e GIA: 80\% de sobrevivência das raizes. 0 valor médio de resistência à fratura ( $N$ ) foi de 280,6 (GNW), 239,0 (GW), 221,3 (GDA) e 234,1 (GIA) sem diferença significante entre os grupos $(p=0,7476)$. Os resultados sugerem similar resistência à fratura em ambos os dentes fragilizados ou não-fragilizados em relação à técnica de reconstrução das paredes radiculares internas. Elevada incidência de fraturas catastróficas foram observadas nos dentes fragilizados sem a restauração das paredes radiculares internas.

\section{References}

1. Chuang S-F, Yaman P, Herrero A, Dennison JB, Chang C-H. Influence of post material and length on endodontically treated incisors: an in vitro and finite element study. J Prosthet Dent 2010;104:379-388.

2. Tang $W, W u Y$, Smales RJ. Identifying and reducing risks for potential fractures in endodontically treated teeth. J Endod 2010;36:609-617.

3. Figueiredo FE, Martins-Filho PR, Faria-e-Silva AL. Do metal postretained restorations result in more root fractures than fiber postretained restorations? A systematic review and meta-analysis. J Endod 2015;41:309-316.

4. Lazari PC, de Oliveira RCN, Anchieta RB, de Almeida EO, Freitas-Junior $A C$, Kina $S$, et al.. Stress distribution on dentin-cement-post interface varying root canal and glass fiber post diameters. A three-dimensional finite element analysis based on micro-CT data. J Appl Oral Sci 2013;21:611-617.

5. Santos-Filho PC, Verissimo C, Soares PV, Saltarelo RC, Soares CJ, Marcondes Martins LR. Influence of ferrule, post system, and length on biomechanical behavior of endodontically treated anterior teeth. J Endod 2014:40:119-123.

6. Alsamadani KH, Abdaziz el-SM, Gad el-S. Influence of different restorative techniques on the strength of endodontically treated weakened roots. Int J Dent 2012;2012:343712.

7. Grandini S, Sapio S, Simonetti M. Use of anatomic post and core for reconstructing an endodontically treated tooth: a case report. J Adhes Dent 2003;5:243-247.

8. Zogheib LV, Pereira JR, do Valle AL, de Oliveira JA, Pegoraro LF. Fracture resistance of weakened roots restored with composite resin and glass fiber post. Braz Dent J 2008;19:329-333.

9. Coelho CS, Biffi JC, Silva GR, Abrahao A, Campos RE, Soares CJ. Finite element analysis of weakened roots restored with composite resin and posts. Dent Mater J 2009;28:671-678.

10. Silva GR, Santos-Filho PC, Simamoto-Júnior PC, Martins LR, Mota $A S$, Soares CJ. Effect of post type and restorative techniques on the strain and fracture resistance of flared incisors roots. Braz Dent J 2011;22:230-237.

11. Barcellos RR, Correia DPD, Farina AP, Mesquita MF, Ferraz CCR, Cecchin D. Fracture resistance of endodontically treated teeth restored with intra radicular posts: the effects of post system and dentine thickness. J Biomech 2013;46:2572-2577.

12. Gomes GM, Gomes $\mathrm{OM}$, Gomes JC, Loguercio AD, Calixto AL, Reis A. Evaluation of different restorative techniques for filling flared root canals: fracture resistance and bond strength after mechanical fatigue. J Adhes Dent 2014;16:267-276.

13. Gomes GM, Rezende EC, Gomes OM, Gomes JC, Loguercio AD, Reis A. Influence of the resin cement thickness on bond strength and gap formation of fiber posts bonded to root dentin. J Adhes Dent 2014;16:71-78.

14. Gomes ÉA, Gueleri DB, da Silva SR, Ribeiro RF, Silva-Sousa YT. Threedimensional finite element analysis of endodontically treated teeth with weakened radicular walls restored with different protocols. J Prosthet Dent 2015;114:383-389.

15. Bonfante $G$, Kaizer $O B$, Pegoraro $L F$, do Valle AL. Fracture strength of teeth with flared root canals restored with glass fiber posts. Int Dent J 2007;57:153-160.

16. Zogheib LV, Saavedra G de $\mathrm{S}$, Cardoso PE, Valera MC, Araújo MA. Resistance to compression of weakened roots subjected to different root reconstruction protocols. J Appl Oral Sci 2011;19:648-654.

17. Santos-Filho PC, Castro CG, Silva GR, Campos RE, Soares CJ. Effects of post system and length on the strain and fracture resistance of root filled bovine teeth. Int Endod J 2008;41,493-501.

18. Franco $E B$, Valle $A L$, Almeida $A L P$, Rubo JH, Pereira JR. Fracture resistance of endodontically treated teeth restored with glass fiber posts of different lengths. J Prosthet Dent 2014;111:30-34.

19. Ambica K, Mahendran K, Talwar S, Verma M, Padmini G, Periasamy R. Comparative evaluation of fracture resistance under static and fatigue loading of endodontically treated teeth restored with carbon fiber posts, glass fiber posts, and an experimental dentin post system: an in vitro study. J Endod 2013;39:96-100.

20. Quek CE, Tan KB, Nicholls JI. Load fatigue performance of a singletooth implant abutment system: effect of diameter. Int J Oral Maxillofac Implants 2006;21:929-936.

21. Braga RR, Boaro LC, Kuroe T, Azevedo CL, Singer JM. Influence of cavity dimensions and their derivates (volume and " $\mathrm{C}$ " factor) on shrinkage stress development and microleakage of composite restorations. Dent Mater 2006;22:818-823.

22. Gomes EA, Diana HH, Oliveira JS, Silva-Sousa YT, Faria AC, Ribeiro RF. Reliability of FEA on the results of mechanical properties of materials. Braz Dent J 2015;26:667-670.

23. Wandscher VF, Bergoli $C D$, Limberger IF, Ardenghi TM, Valandro LF. Preliminary results of the survival and fracture load of roots restored with intracanal posts: weakened vs nonweakened roots. Oper Dent 2014;39:541-555.

24. Wandscher VF, Bergoli $C D$, de Oliveira $A F$, Kaizer $O B$, Souto Borges $A L$, Limberguer I da $F$, et al.. Fatigue surviving, fracture resistance, shear stress and finite element analysis of glass fiber posts with different diameters. J Mech Behav Biomed Mater 2015;43:69-77.

25. Goracci $C$, Fabianelli A, Sadek FT, et al.. The contribution of friction to the dislocation resistance of bonded fiber posts. J Endod 2005;31:608612 .
Received June 15, 2016 Accepted September 13, 2016 